(2) Open Access Full Text Article

\title{
Impact of preoperative chronic renal failure on liver transplantation: a population-based cohort study
}

Peter Chi-Ho Chung ${ }^{1,2}$ Hsiu-Pin Chen ${ }^{1,2}$

Jr-Rung $\operatorname{Lin}^{3,4}$

Fu-Chao Liu',

Huang-Ping Yu ${ }^{1,2}$

'Department of Anesthesiology, Chang Gung Memorial Hospital, ${ }^{2}$ College of Medicine, ${ }^{3} \mathrm{Clinical}$ Informatics and Medical Statistics Research Center, ${ }^{4} \mathrm{Graduate}$ Institute of Clinical Medicine, Chang Gung University, Taoyuan, Taiwan
This article was published in the following Dove Press journal:

Therapeutics and Clinical Risk Management

14 December 2016

Number of times this article has been viewed

Purpose: The purpose of this study was to assess whether preoperative chronic renal failure (CRF) affects the rates of postoperative complications and survival after liver transplantation. Methods: This population-based retrospective cohort study included 2,931 recipients of liver transplantation performed between 1998 and 2012, enrolled from the Taiwan National Health Insurance Research Database. Patients were divided into two groups, based on the presence or absence of preoperative CRF.

Results: The overall estimated survival rate of liver transplantation recipients (LTRs) with preoperative CRF was significantly lower than that of patients without preoperative CRF $(P=0.0085)$. There was no significant difference between the groups in terms of duration of intensive care unit stay, total hospital stay, bacteremia, postoperative bleeding, and pneumonia during hospitalization. Long-term adverse effects, including cerebrovascular disease and coronary heart disease, were not different between patients with versus without CRF.

Conclusion: These findings suggest that LTRs with preoperative CRF have a higher rate of mortality.

Keywords: chronic renal failure, cohort study, survival rate, liver transplantation, populationbased study

\section{Introduction}

Liver transplantation is currently a mainstay treatment of hepatoma and hepatic failure worldwide. ${ }^{1,2}$ In liver transplantation recipients (LTRs), renal insufficiency may increase the duration of intensive care unit (ICU) stay, incidence of postoperative stroke, infection, and even therapeutic cost. ${ }^{3-9}$ Additionally, a higher mortality rate was reported in patients with renal insufficiency. ${ }^{4,9}$ Nevertheless, renal injury that is most commonly discussed in this population is that related to immunosuppressive agents that are routinely administered to LTRs. ${ }^{10-14}$

To the best of our knowledge, there are relatively few population-based studies on postoperative outcome and long-term follow-up of LTRs with preoperative renal failure. ${ }^{15,16}$ Our population-based cohort study was designed to analyze the mortality rate and intraoperative and postoperative complications related to preoperative renal failure in LTRs.

\section{Materials and methods Data collection}

The Bureau of National Health Insurance established the National Health Insurance Research Database (NHIRD) in 1992, and provides de-identified and computerized 
data from this database. All of Taiwan's National Health Service hospital management data, including admissions, can be obtained. We conducted a retrospective, populationbased, cohort study from the NHIRD. The database contains basic patient information and hospital medical data of the raw hospital medical claims, including clinical diagnostic codes based on the International Classification of Disease, Revision 9, Clinical Modification (ICD-9-CM). According to the National Health Insurance, a transplant surgeon or gastroenterologist must diagnose patients who require liver transplant.

This study was evaluated and approved by the institutional review board of Chang Gung Memorial Hospital (CGMH-103-0102B) and the NHIRD research committee (NHIRD-103-103). As per institutional review board guidelines all personal information was fully encrypted; therefore, patient informed consent was exempted.

\section{Study design}

Figure 1 shows the flowchart for patient identification and selection. LTRs were identified from the NHIRD using ICD-9-CM codes V427 (liver transplant status) and 996.82 (complications of transplanted liver) between July 1998, when liver transplant was first paid for by health insurance in Taiwan, and December 2012. Over this period, 4,086 LTRs were registered in the NHIRD. This prospective group of patients was reviewed, and LTRs who did not undergo transplantation in Taiwan were excluded. Applying this criterion, 1,148 patients were excluded due to the absence of a liver transplant surgery code (505, 75020A, 75020B). The final study cohort consisted of 2,938 LTRs.

We separated our patients into two groups, LTRs with chronic renal failure (CRF) and without CRF. We defined the group with CRF based on preoperative diagnostic codes for CRF (ICD-9-CM 585, V451, V56) or management of dialysis codes (ICD-9-CM 38.95, 39.27, 39.42, 39.95, 39.43, 54.98). We excluded patients having only the diagnostic code for acute renal failure (ICD-9-CM 584). Based on this classification, the cohort study consisted of 123 patients with CRF and 2,808 patients without CRF.

Preoperative medical comorbidities were identified from diagnosis in outpatient departments or inpatient departments. All diagnoses were verified using the ICD-9-CM codes as follows: hypertension (ICD-9-CM 401-405), pulmonary diseases (ICD-9-CM 490-496, A323, A325), diabetes mellitus (ICD-9-CM 250, A181), cerebrovascular disease (ICD-9-CM 430-438, A291-A299), coronary heart disease (ICD-9-CM 410-414, A279), congestive heart failure (ICD-9-CM 428, A289), vascular disease (ICD-9-CM 443, 444, A302), chronic hepatitis (ICD-9-CM 070, 571, 573.3, A347), and esophageal varices (ICD-9-CM 456). Postoperative medical morbidities were also verified using the ICD-9-CM codes as follows: bacteremia (ICD-9-CM 038, 998.5), pneumonia (ICD-9-CM 480486), and postoperative bleeding (ICD-9-CM 998.0-998.2).

\section{Measurements}

Primary outcome measures were estimated survival rates during the first postoperative year and the overall 14.5-year

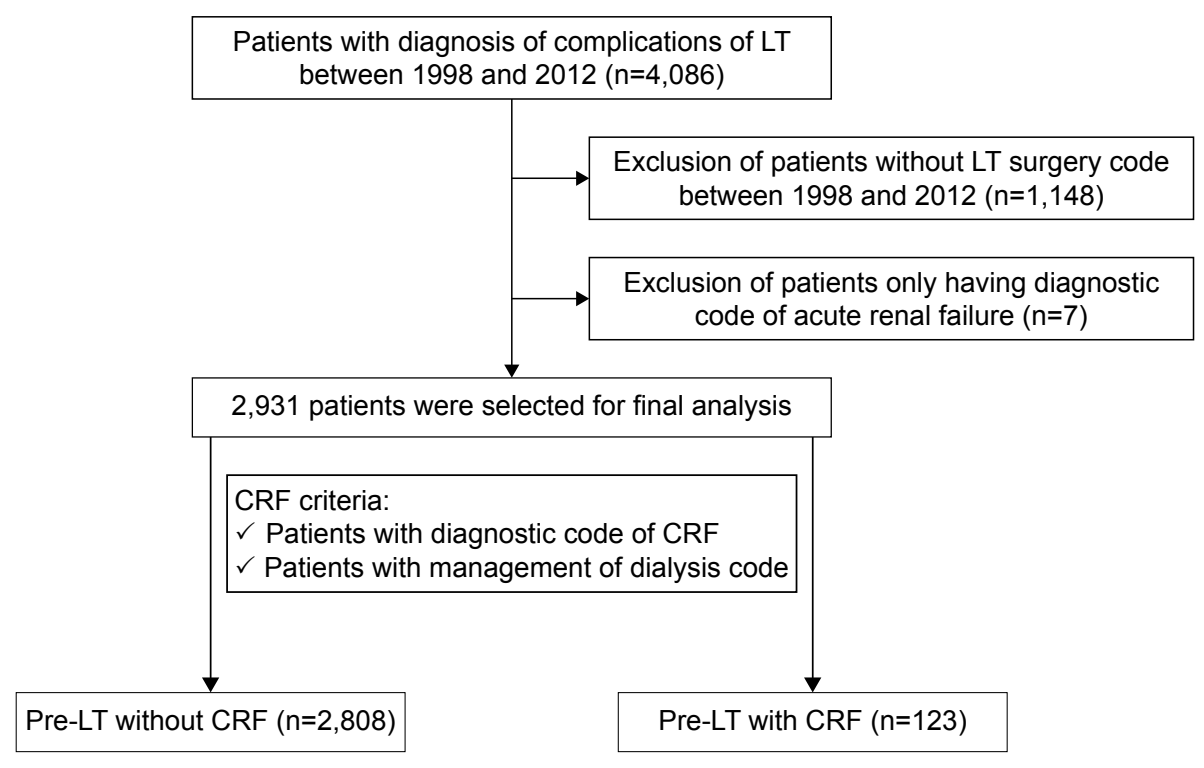

Figure I Study design and flowchart for patient selection. Abbreviations: LT, liver transplant; CRF, chronic renal failure. 
follow-up period. Other outcomes included duration of stay in the ICU, total duration of hospital stay, bacteremia, postoperative bleeding, and pneumonia during the hospitalization period. Long-term adverse effects after the hospitalization period included bacteremia, cerebrovascular disease, and coronary heart disease. Outcomes were compared between patients with and without CRF. Survival time was calculated from the date of liver transplantation surgery to the date of death.

\section{Statistical analysis}

Between-group differences in the distribution of demographic data, coexisting medical conditions, use of inpatient medical services (including length of hospitalization and ICU stay), and rates of postoperative complications were evaluated using $t$-test, chi-squared test, or Fisher's exact test, as appropriate, for the type and distribution of the data. Kaplan-Meier estimates with log-rank tests were used to compare between-group survival during the follow-up period. For the analysis of mortality, patients were followed up until an event (death) or censoring (loss to follow-up or end of the follow-up period), whichever occurred first. All analyses were performed using SAS software (version 9.3; SAS Institute Inc., Cary, NC, USA), with a two-sided $P$-value $<0.05$ considered to be statistically significant.

\section{Results}

The demographic data reported in Table 1 show that LTRs with CRF were commonly diagnosed with hypertension, diabetes, or coronary heart disease.
Figures 2 and 3 show the unadjusted Kaplan-Meier survival curves after liver transplantation during the first postoperative year and over 14.5-year follow-up, respectively. The estimated survival rate of LTRs with CRF was significantly lower than that of LTRs without CRF $(P=0.0413$ and 0.0085 , respectively).

Table 2 shows the outcomes during hospitalization. Duration of stay in the ICU and hospital was not significantly different between the groups. Incidence of bacteremia, pneumonia, and postoperative bleeding was also not significantly different.

Morbidities after the hospitalization period are listed in Table 3. The rates of cerebrovascular disease and coronary heart disease were not significantly different between the groups.

\section{Discussion}

Patients with renal disease are assumed to have a higher rate of cardiovascular mortality, and patients with renal disease accompanied by diabetes are expected to progressively worsen over time. ${ }^{17-19}$ The global dialysis population was estimated to be approximately 1.1 million in 2001, and the size of this population was expected to increase by $7 \%$ per year. ${ }^{20}$ The study was designed to evaluate the impact of preoperative renal failure on the LTRs. The 2002 cohort study of 20,281 patients from Nair et al was the most recent large population-based study to evaluate preoperative kidney failure in LTRs; ${ }^{16}$ it primarily analyzed the survival rate of patients receiving liver transplantation. Our findings

Table I General demographics of the study subjects with or without CRF preoperatively

\begin{tabular}{|c|c|c|c|}
\hline Characteristics & With CRF $(n=123)$ & Without CRF $(n=2,808)$ & $P$-value \\
\hline Age (mean [SD]) & $46.76(18.80)$ & $46.42(17.65)$ & 0.8356 \\
\hline Gender & & & 0.1893 \\
\hline Female & 30 (24.39) & $840(29.91)$ & \\
\hline Male & $93(75.61)$ & I,968 (70.09) & \\
\hline \multicolumn{4}{|c|}{ Preoperative clinical parameters } \\
\hline Hypertension & 44 (35.77) & $556(19.80)$ & $<0.0001$ \\
\hline Pulmonary diseases & $23(18.70)$ & $397(14.14)$ & 0.1576 \\
\hline Diabetes mellitus & $42(34.15)$ & 57I (20.33) & 0.0002 \\
\hline Cerebrovascular disease & $8(6.50)$ & $87(3.10)$ & 0.0597 \\
\hline Coronary heart disease & 14 (I I.38) & $190(6.77)$ & 0.0490 \\
\hline Congestive heart failure & $6(4.88)$ & $44(1.57)$ & 0.0169 \\
\hline Vascular disease & $\mathrm{I}(0.8 \mathrm{I})$ & $16(0.57)$ & 0.5185 \\
\hline \multicolumn{4}{|l|}{ Chronic hepatitis } \\
\hline Alcoholic hepatitis & $35(28.46)$ & $523(18.63)$ & 0.0066 \\
\hline Hepatitis B & $58(47.15)$ & I,353 (48. I8) & 0.8231 \\
\hline Hepatitis C & $22(\mid 7.89)$ & $502(17.88)$ & 0.9980 \\
\hline Esophageal varices & 38 (30.89) & $\mathrm{I}, 029(36.65)$ & 0.1945 \\
\hline
\end{tabular}

Notes: Chi-squared test, $t$-test, or Fisher's exact test was used to examine the differences in the demographic characteristics of liver transplant recipients. Values presented as $\mathrm{n}(\%)$ unless otherwise indicated.

Abbreviations: CRF, chronic renal failure; SD, standard deviation. 


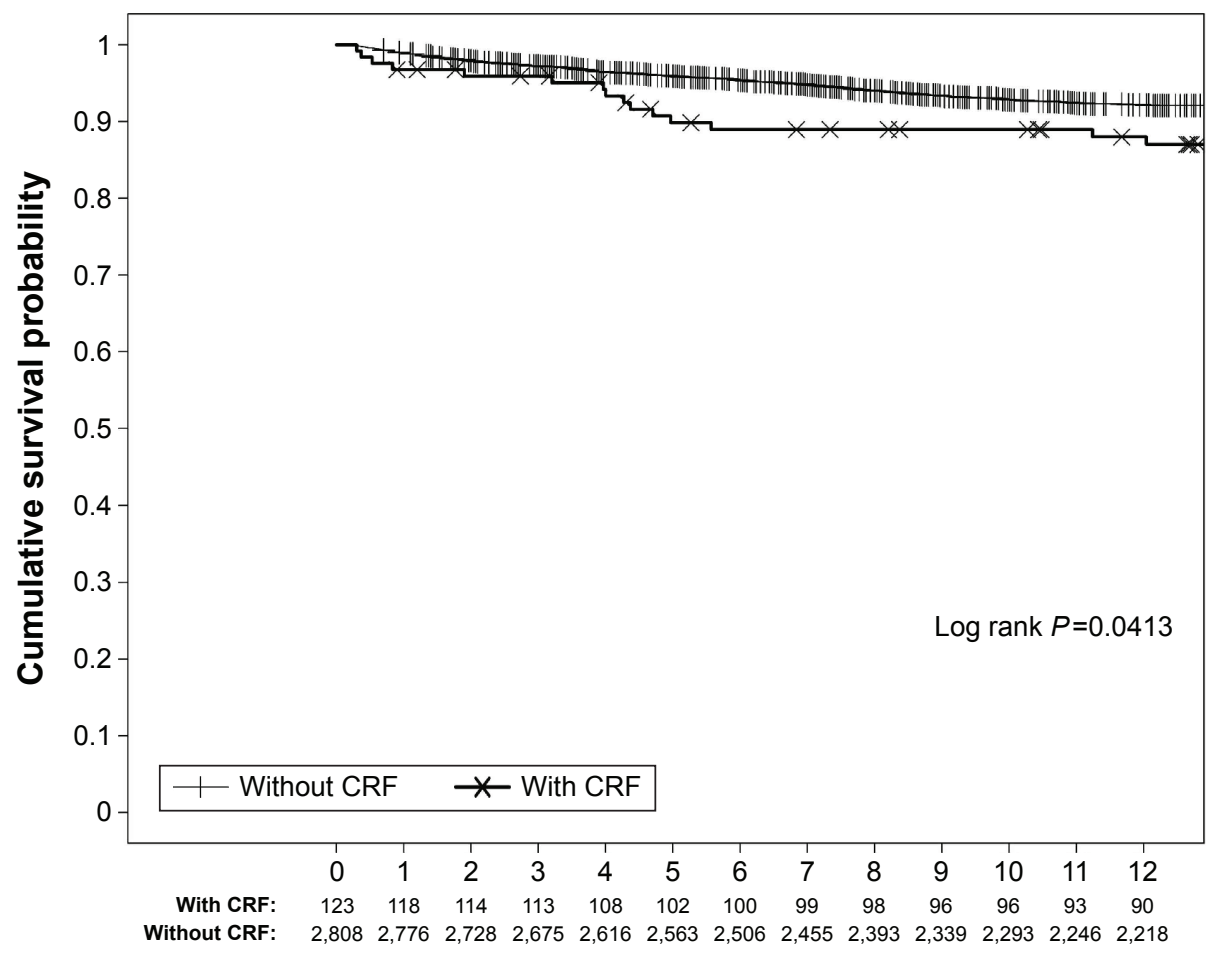

Follow-up time (months)

Figure 2 Unadjusted Kaplan-Meier survival curves of patient survival during the first year after liver transplantation. Abbreviation: CRF, chronic renal failure.

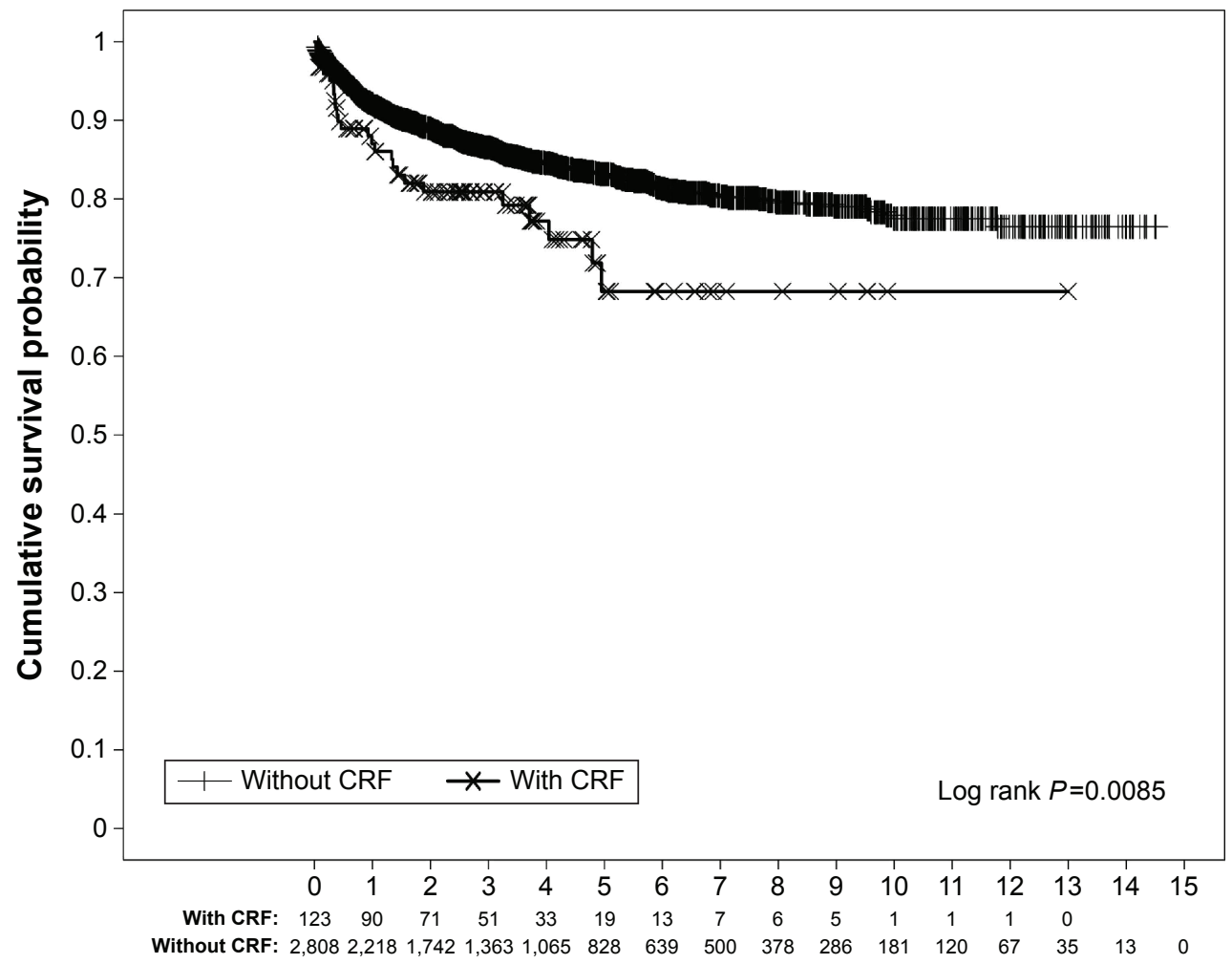

Follow-up time (years)

Figure 3 Unadjusted Kaplan-Meier survival curves of patient survival I4.5 years after liver transplantation. Abbreviation: CRF, chronic renal failure. 
Table 2 Outcome characteristics of liver transplant recipients with or without CRF

\begin{tabular}{llll}
\hline Characteristics & With CRF (n=I 23) & Without CRF (n=2,808) & P-value \\
\hline ICU stay (days), mean (SD) & I5.56 (I6.30) & I6.0I (I7.I2) & 0.7777 \\
Hospital stay (days), mean (SD) & $48.80(32.64)$ & $48.47(34.99)$ & 0.9198 \\
Bacteremia, n (\%) & $8(6.50)$ & $156(5.56)$ & 0.6542 \\
Pneumonia, n (\%) & $3(2.44)$ & $83(2.96)$ & 1.0000 \\
Postoperative bleeding, n (\%) & $4(3.25)$ & $146(5.20)$ & 0.3374 \\
\hline
\end{tabular}

Note: Chi-squared test, $t$-test, or Fisher's exact test was used to examine the differences of liver transplant recipients.

Abbreviations: CRF, chronic renal failure; SD, standard deviation; ICU, intensive care unit.

confirm and extend those of Nair et al. ${ }^{16}$ In our cohort study of 2,931 patients, we studied not only the survival rate but also intraoperative and postoperative complications during 14.5-year follow-up. Consistent with previous findings, we found that the estimated survival rate was significantly lower in LTRs with CRF.

In Table 1, it was not surprising to note that hypertension, diabetes mellitus, coronary heart disease, and alcoholic hepatitis were common in the CRF group. Diabetes is the leading cause of renal failure, and alcoholic hepatitis is also a common cause, and hypertension and coronary heart disease are related to pathophysiology of renal failure..$^{21,22}$ Diabetes induces renal damage and coronary heart disease, and thus, patients with diabetes-related renal failure are expected to have a higher rate of coronary artery disease. CRF group with hypertension, diabetes, congestive heart failure, and alcoholic hepatitis is suggested to be associated with renal dysfunction or comorbidities. In addition, there were no patients in group with CRF who received renal transplantation.

During the hospitalization period, there was no significant difference between the groups in terms of postoperative bleeding, bacteremia, or pneumonia, suggesting that preoperative renal failure in LTRs might not affect the coagulation system or the incidence of infection in the perioperative period. ICU stay and hospital stay were also not significantly different between the two groups. Previous reports found that preoperative renal insufficiency prolonged the ICU stay and cost; we considered that the health care policy of different countries might play an important role in this regard. ${ }^{23,24}$ In Taiwan, almost $99.9 \%$ of the population are included in the government health insurance plan, and the hospital stay and ICU stay are tightly controlled because of the fixed and limited annual budget for medical expenses of each hospital.

Postoperative cerebrovascular disease and coronary heart disease were not significantly different between the groups (Table 3). Patients with preoperative coronary heart disease were excluded from the analysis. Post-liver transplant morbidities of LTRs with or without CRF were similar in the present study. Cerebrovascular disease and coronary heart disease may lead to increase in postoperative mortality. It remains to be determined in further studies. Although incidences of these postoperative complications were similar between the groups in our study, we speculate that LTRs with preoperative renal failure might have a poorer prognosis and higher mortality rate, thus leading to lower estimated survival rate. This remained to be determined in a further study.

Our study has several limitations. NHIRD is a database that primarily collects claim codes for reimbursement; thus, we could only identify the patient with codes for CRF and dialysis but not the laboratory data to evaluate their renal function in detail, such as creatinine clearance, a commonly used indicator of renal failure. ${ }^{17}$ The characteristics of complications also could not be identified based on the codes used, such as thrombotic versus hemorrhagic cerebrovascular disease. The severity of complications such as coronary heart disease or bacteremia is strongly related to patient mortality; however, we could not determine disease severity based on the codes used in the database.

Table 3 Post-liver transplant morbidities of liver transplant recipients with or without CRF

\begin{tabular}{|c|c|c|c|c|c|}
\hline \multirow[t]{2}{*}{ Characteristics } & \multicolumn{2}{|c|}{ With CRF (n=I23) } & \multicolumn{2}{|c|}{ Without CRF $(n=2,808)$} & \multirow[t]{2}{*}{$P$-value } \\
\hline & n & $\%$ & n & $\%$ & \\
\hline Cerebrovascular disease & 0 & 0.00 & 44 & 1.57 & 0.2601 \\
\hline Coronary heart disease & 2 & 1.63 & 82 & 2.92 & 0.7735 \\
\hline
\end{tabular}

Note: Chi-squared test, $t$-test, or Fisher's exact test was used to examine the differences in post-liver transplant morbidities of liver transplant recipients. Abbreviation: CRF, chronic renal failure. 


\section{Conclusion}

Our results indicate that survival rate in LTRs is related to preoperative CRF. In our cohort study, LTRs with CRF had a significant lower estimated survival rate than that of LTRs without CRF despite similar rates of bacteremia, pneumonia, coronary heart disease, and postoperative bleeding.

\section{Acknowledgments}

This study was based in part on data from the NHIRD provided by the Bureau of National Health Insurance, Department of Health, and managed by the National Health Research Institutes. The interpretation and conclusions contained herein do not represent those of the National Health Insurance Administration, Department of Health, or National Health Research Institutes. This work was partially supported by grants from the Chang Gung Memorial Hospital (CORPG3E0131) to Huang-Ping Yu.

\section{Disclosure}

The authors report no conflicts of interest in this work.

\section{References}

1. Bhardwaj N, Perera MT, Silva MA. Current treatment approaches to HCC with a special consideration to transplantation. J Transplant. 2016; 2016:7926264.

2. Kaido T. Selection criteria and current issues in liver transplantation for hepatocellular carcinoma. Liver Cancer. 2016;5(2):121-127.

3. Brown RS Jr, Lombardero M, Lake JR. Outcome of patients with renal insufficiency undergoing liver or liver-kidney transplantation. Transplantation. 1996;62(12):1788-1793.

4. Afonso RC, Hidalgo R, Zurstrassen MPVC, et al. Impact of renal failure on liver transplantation survival. Transplant Proc. 2008;40(3): 808-810.

5. Rossi AP, Vella JP. Acute kidney disease after liver and heart transplantation. Transplantation. 2016;100(3):506-514.

6. Pham PT, Pham PC, Wilkinson AH. Management of renal dysfunction in the liver transplant recipient. Curr Opin Organ Transplant. 2009;14(3): 231-239.

7. Lima EQ, Zanetta DM, Castro I, et al. Risk factors for development of acute renal failure after liver transplantation. Ren Fail. 2003;25(4): 553-560.

8. Brown RS Jr, Lake JR, Ascher NL, Emond JC, Roberts JP. Predictors of the cost of liver transplantation. Liver Transpl Surg. 1998;4(2): 170-176.
9. Castells L, Baliellas C, Bilbao I, et al. Detección precoz, prevención y manejo de la insuficiencia renal en el trasplante hepático. [Early detection, prevention and management of renal failure in liver transplantation]. Gastroenterol Hepatol. 2014;37(8):480-491. Spanish.

10. Varo E, López A, Rivero C. Initial immunosuppression in liver transplant recipients with impaired renal function. Transplant Proc. 2005; 37(9):3909-3912.

11. Rais-Jalali GA, Sagheb MM, Daniali F, et al. Acute renal failure in the first 100 orthotopic liver transplant patients in Southern Iran. Exp Clin Transplant. 2007;5(2):710-712.

12. Lewandowska L, Matuszkiewicz-Rowinska J. Acute kidney injury after procedures of orthotopic liver transplantation. Ann Transplant. 2011;16(2):103-108.

13. Gámán G, Gelley F, Gerlei Z, et al. Veseérintettség májátültetés során. [Kidney function and liver transplantation]. Orv Hetil. 2013; 154(26): 1018-1025. Hungarian.

14. Gonwa TA, Klintmalm GB, Levy M, Jennings LS, Goldstein RM, Husberg BS. Impact of pretransplant renal function on survival after liver transplantation. Transplantation. 1995;59(3):361-365.

15. Tojimbara T, Fuchinoue S, Nakajima I, et al. Factors affecting survival after living-related liver transplantation. Transpl Int. 2000;13 Suppl 1: S136-S139.

16. Nair S, Verma S, Thuluvath PJ. Pretransplant renal function predicts survival in patients undergoing orthotopic liver transplantation. Hepatology. 2002;35(5):1179-1185.

17. Afkarian M, Sachs MC, Kestenbaum B, et al. Kidney disease and increased mortality risk in type 2 diabetes. J Am Soc Nephrol. 2013; 24(2):302-308.

18. Tonelli M, Wiebe N, Culleton B, et al. Chronic kidney disease and mortality risk: a systematic review. J Am Soc Nephrol. 2006;17(7): 2034-2047.

19. Grigorian Shamagian L, Varela Román A, Pedreira Pérez M, Gómez Otero I, Virgós Lamela A, González-Juanatey JR. La insuficiencia renal es un predictor independiente de la mortalidad en pacientes hospitalizados por insuficiencia cardíaca y se asocia con un peor perfil de riesgo cardiovascular. [Renal failure is an independent predictor of mortality in hospitalized heart failure patients and is associated with a worse cardiovascular risk profile]. Rev Esp Cardiol. 2006;59(2):99-108. Spanish.

20. Lysaght MJ. Maintenance dialysis population dynamics: current trends and long-term implications. J Am Soc Nephrol. 2002;13 Suppl 1: S37-S40.

21. Arora R, Kathuria S, Jalandhara N. Acute renal dysfunction in patients with alcoholic hepatitis. World J Hepatol. 2011;3(5):121-124.

22. Schena FP, Gesualdo L. Pathogenetic mechanisms of diabetic nephropathy. J Am Soc Nephrol. 2005;16 Suppl 1:S30-S33.

23. Mainous AG 3rd, Diaz VA, Everett CJ, Knoll ME. Impact of insurance and hospital ownership on hospital length of stay among patients with ambulatory care sensitive conditions. Ann Fam Med. 2011;9(6): 489-495.

24. Reinhardt UE. Health insurance and health policy in the Federal Republic of Germany. Health Care Financ Rev. 1981;3(2):1-14.
Therapeutics and Clinical Risk Management

\section{Publish your work in this journal}

Therapeutics and Clinical Risk Management is an international, peerreviewed journal of clinical therapeutics and risk management, focusing on concise rapid reporting of clinical studies in all therapeutic areas, outcomes, safety, and programs for the effective, safe, and sustained use of medicines. This journal is indexed on PubMed Central, CAS,

\section{Dovepress}

EMBase, Scopus and the Elsevier Bibliographic databases. The manuscript management system is completely online and includes a very quick and fair peer-review system, which is all easy to use. Visit $\mathrm{http}: / / \mathrm{www}$.dovepress.com/testimonials.php to read real quotes from published authors. 